\title{
Competências docentes em matemática por meio do ensino híbrido: um olhar para a recomendação pedagógica
}

\author{
Núbia Guimarães ${ }^{1}$, Patricia Alejandra Behar ${ }^{2}$, Márcia Notare ${ }^{3}$ \\ ${ }^{1}$ Instituto Federal do Rio Grande do Sul - IFRS Campus Canoas \\ Canoas - RS - Brasil \\ ${ }^{2,3}$ Universidade Federal do Rio Grande do Sul - UFRGS \\ Porto Alegre - RS - Brasil \\ nubia.guimaraes@canoas.ifrs.edu.br, \{patricia.behar,marcia.notare\}@ufrgs.br
}

Abstract. This paper aims to analyze the contribution of the pedagogical recommendation for the construction of the necessary competences to the mathematics teacher in the hybrid teaching modality. For this, a mapping will be carried out to build a matrix of teaching competences in mathematics. After validation by experts, pedagogical recommendation will be made and analyzed using a competence-based recommendation system. One of the results of this research is the competence matrix, a reference for the teacher in order to enable the integral formation of the student. The other is that the pedagogical recommendation brings important contributions to the teacher in training in this research and can later be expanded to use in other contexts.

Resumo. Este trabalho pretende analisar a contribuição da recomendação pedagógica na construção das competências necessárias ao professor de matemática por meio do ensino híbrido. Para isso, será realizado um mapeamento para a construção de uma matriz de competências docentes em matemática. Após validação por especialistas, será realizada e analisada a recomendação pedagógica usando o recomendador baseado em competências. Um dos resultados dessa pesquisa é a matriz de competências, um referencial para o professor com vistas a possibilitar a formação integral do aluno. O outro é que a recomendação pedagógica traga contribuições importantes para o professor em formação nesta pesquisa $e$, posteriormente, possa ser ampliada para utilização em outros contextos.

\section{Introdução}

A motivação para tal pesquisa tem origem nas experiências de sala de aula, reflexões a partir de reuniões pedagógicas e estudos relacionados, não se limitando a esses. É bastante conhecido o problema que se refere às dificuldades encontradas pelos alunos na disciplina de matemática no ensino básico. Essas dificuldades são cumulativas e afetam drasticamente o desempenho dos alunos nos cursos superiores com ênfase nas ciências exatas. Isso é facilmente verificado pelo alto índice de desistência e reprovação, resultando em um número bastante reduzido de formandos. Um exemplo disso pode ser visto na última sinopse estatística da educação superior fornecida pelo INEP, de 2017 atualizada em 29/09/18, onde um total de 95.004 estudantes matriculados em cursos de formação de professores de matemática, há apenas 10.730 concluintes. 
VIII Congresso Brasileiro de Informática na Educação (CBIE 2019)

Anais dos Workshops do VIII Congresso Brasileiro de Informática na Educação (WCBIE 2019)

Segundo Becker (2012), algumas concepções epistemológicas errôneas são muito comuns e determinantes na ação (in)adequada ou na falta de ação do professor diante desses obstáculos. Em sua pesquisa sobre a epistemologia do professor de matemática, o referido autor identificou duas crenças muito frequentes entre os docentes desta área, em ambas concepções o sujeito é passivo, quando aprender matemática exige o protagonismo do aprendiz na construção do seu próprio conhecimento:

“'[...] o progresso dos conhecimentos é obra de uma união indissociável entre a experiência e a dedução, de uma colaboração necessária entre os dados oferecidos pelo objeto e as ações ou operações que constituem o quadro lógico-matemático [...]”" (PIAGET, 1972, p. 93)

Moran (2018), em concordância, diz que a vida é um processo de aprendizagem ativa, onde o sujeito aprende e amplia as suas competências por processos abertos e progressivamente mais complexos. Além disso, crianças e jovens estão cada vez mais conectados às tecnologias digitais, fazendo parte de uma geração que estabelece novas relações com o conhecimento, requerendo que transformações aconteçam na escola (BACICH, 2015). E, segundo (BEHAR, 2013), a sociedade atual está sendo pautada pela tríade: informação, conhecimento e aprendizagem, gerando mudanças que vêm exigindo que os profissionais tenham capacidade para atuar frente a diferentes situações. É fácil perceber que o ensino que requer do aluno apenas prestar atenção, copiar e repetir não é suficiente para atender essas demandas, tornando-se necessário o desenvolvimento também de habilidades e atitudes.

Dessa forma, fica evidente a importância do investimento em pesquisas a respeito da formação inicial e continuada de professores com vistas a contribuir para que ocorram as mudanças necessárias nas formas de aprender e ensinar. Os professores e futuros professores de matemática precisam estar capacitados para dialogar com essa realidade da sala de aula, atuando como mediadores e não mais como protagonistas na aprendizagem. Para isso, tornase necessário pensar acerca das competências necessárias à função docente, refletindo sobre a natureza do trabalho pedagógico e procurando considerar todos os campos que caracterizam o trabalho docente.

Neste trabalho, vamos analisar as contribuições da recomendação pedagógica baseada em competências por meio do ensino híbrido. Segundo Paiva, Bittencourt e Silva (2013), as recomendações pedagógicas têm o objetivo de oferecer orientações para superar dificuldades, aprimorando a experiência de aprendizagem do sujeito. Os recursos educacionais recomendados, por sua vez, podem contribuir para a construção e aprimoramento de Conhecimentos (saber), Habilidades (saber fazer) e Atitudes (saber ser), elementos das competências conhecidos pela sigla CHA, visando a formação integral do sujeito.

A presente pesquisa teve início em janeiro do presente ano. Esse trabalho se desenvolverá na linha de pesquisa Ambientes Informatizados e Educação à Distância do Programa de Pós-graduação em Informática na Educação (PGIE) da Universidade Federal do Rio Grande do Sul (UFRGS) e tem como questão de pesquisa: "De que forma a recomendação pedagógica pode contribuir para a construção das competências docentes em matemática por meio do ensino híbrido?" 
VIII Congresso Brasileiro de Informática na Educação (CBIE 2019)

Anais dos Workshops do VIII Congresso Brasileiro de Informática na Educação (WCBIE 2019)

\section{Referencial teórico}

A concepção de competência nesta pesquisa refere-se ao estudo da Teoria das Competências de Perrenoud (2000) que afirma que, antes de nos inserirmos como educadores em atividades pedagógicas relativas aos processos de ensino e aprendizagem, devemos reconhecer nossas próprias competências individuais, procurando mapear nossas possibilidades e limites na execução do trabalho. As competências já desenvolvidas devem ser adequadas aos usos a que se destinam, mobilizando outras competências relativas à capacidade de avaliação. Esse processo avaliativo pode auxiliar o trabalho do professor em sala de aula, bem como impulsionar tal profissional à busca de cursos de formação continuada. O uso do termo competência é uma consequência da necessidade de superar um ensino que se reduziu à memorização (ZABALA e ARNAU, 2010). Entende-se que não são apenas habilidades ou conhecimentos, mas uma combinação destes com as atitudes que compõem as competências (BEHAR, 2013). Assim, as competências são estruturadas por meio dos seus elementos, Conhecimentos, Habilidades e Atitudes (CHA), a serem investigados por meio desta pesquisa.

A abordagem das competências na educação se dá em uma perspectiva do construtivismo piagetiano. A construção do conhecimento em Piaget não refere-se ao mero conhecimento do conteúdo, mas a construção de formas, capacidades, de estruturas cognitivas. Durante a construção de uma competência, o sujeito passa por raciocínios explícitos, decisões conscientes, inferências e hesitações, ensaios e erros (Perrenoud, 2000). Os conflitos permitem o desequilíbrio das certezas, a reflexão e posterior reconstrução em outro patamar. Segundo Piaget (1972), o processo de equilibração é a ação estruturante e organizadora do sujeito, que num processo de espiral vai aperfeiçoando as suas estruturas cognitivas. A matemática, conhecida como uma construção humana para interpretar o mundo, é oriunda de um processo de ação reflexionante sobre este. E é a dialética entre a observação, percepção e reflexão o caminho para a construção do conhecimento.

Nessa perspectiva, essa pesquisa investigará as competências necessárias ao professor de matemática também na modalidade de ensino semipresencial, pelo fato da tendência na reformulação dos cursos superiores em oferecer vinte por cento da carga horária por Ensino à Distância. Nessa forma de ensino, docentes e discentes podem ensinar e aprender em tempos e locais variados, permitindo a mistura (blended) entre o ensino presencial e a distância. O termo Ensino Híbrido (blended Learning), tem aí a sua origem, mas evoluiu para abarcar um conjunto mais rico de estratégias ou dimensões de aprendizagem, estando enraizado a uma ideia de que não existe uma única forma de aprender e que a aprendizagem é um processo contínuo (MARTINS, 2016). Também é interesse dessa pesquisa analisar as competências necessárias aos professores de matemática para o desenvolvimento dessas metodologias que conjugam atividades online e offline que tem sido amplamente utilizadas na atualidade.

A recomendação pedagógica de que trata essa pesquisa surge para resolver uma demanda oriunda do atual estágio da informatização. Ainda é necessário muito tempo à procura de informações, produtos ou serviços na internet. Os repositórios auxiliam nessa prática, mas atuam apenas na recuperação de informações a partir de termos de busca informados pelo usuário. Alguns dos problemas enfrentados nesse contexto são a inexperiência do usuário na realização da busca, o volume e a relevância de itens retornados. Os sistemas de recomendação (SR) permitem, de forma rápida e precisa, indicar as 
VIII Congresso Brasileiro de Informática na Educação (CBIE 2019)

Anais dos Workshops do VIII Congresso Brasileiro de Informática na Educação (WCBIE 2019)

informações mais pertinentes às preferências e necessidades do sujeito. Isso porque os SR cruzam informações do perfil do usuário com características dos itens a serem recomendados, utilizando diferentes tipos de filtragem de informação. Esses sistemas permitem interpretar os hábitos do usuário na internet, oferecendo conteúdo que possa atender às suas preferências.

Essas plataformas estão sendo cada vez mais incorporadas a objetivos pedagógicos, dando origem aos Sistemas de Recomendação Educacionais (SRE). Esses sistemas se tornaram um forte aliado educacional, permitindo a personalização e a adequação de práticas pedagógicas de acordo com as necessidades do aluno. Os SRE também podem colaborar com a gestão dos estudos dos alunos, identificando necessidades que possam ser ainda desconhecidas pelo estudante, indicando recursos educacionais convenientes ao estágio do seu processo de construção de conhecimento. Para Cazella et al. (2012) os SRE funcionam como filtros de informação, encaminhando o conteúdo que melhor atende o usuário frente às suas necessidades e interesses de aprendizado.

Os SRE baseados em competências podem contribuir para a formação integral do sujeito, pois não focam suas recomendações apenas no conhecimento científico, mas no equilíbrio entre a teoria e a prática. Ao indicar materiais sobre determinado tema, consideram quais os CHA que precisam ser desenvolvidos ou aprimorados pelo usuário. Um destes sistemas, é o Recomendador de Objetos de Aprendizagem baseados em competências (RecOAComp), que tem como objetivo filtrar OA com foco no perfil do usuário, baseado nas competências que precisam ser (re)construídas.

\section{Procedimentos metodológicos}

A presente pesquisa é de natureza aplicada, visto que gera conhecimentos de aplicação prática e dirigidos à solução de problemas específicos. A abordagem é qualitativa e é uma pesquisa do tipo exploratória na primeira parte e estudo de caso na segunda. A população da pesquisa será composta por estudantes e professores dos cursos de Licenciatura em Matemática e professores egressos desse curso. As etapas para desenvolvimento da presente pesquisa constarão de (1) revisão de literatura, (2) mapeamento e validação de uma matriz de competências docentes em matemática, (3) estudo de caso, (4) análise e discussão dos resultados e (5) conclusões e trabalhos futuros.

Primeiramente, será realizada a exploração do referencial teórico sobre os principais conceitos e temas envolvidos pela pesquisa. Após, será efetuado o mapeamento das competências necessárias ao professor de matemática, que ocorrerá em três fases. Na primeira, será elaborado um mapeamento com base em análise bibliográfica e documental, obtendo uma matriz de competências e seus elementos (CHA) inicial. Na segunda, será realizada uma oficina de mapeamento de competências com professores dos cursos de Licenciatura em Matemática e professores egressos desse curso. Na terceira, ocorrerá o cruzamento entre os dois primeiros, denotando o mapeamento preliminar. Para validação, a matriz de competências será submetida à análise de especialistas por meio de um grupo focal e, por fim, enviada a vários especialistas no Brasil por meio de um questionário.

Após a obtenção da matriz de competências necessárias para a formação docente em matemática, será realizado um estudo de caso para análise da contribuição da recomendação pedagógica na construção de competências por meio do recomendador de OA RecOAComp. 
Para isso, inicialmente será feita a análise documental de um curso de Licenciatura em Matemática, para verificar a existência de um gap de competências, ou seja, a diferença entre as competências propostas no curso e as necessárias, apontadas pela matriz de competências. A partir daí, um curso de extensão será proposto com o intuito de construir as competências identificadas no gap, utilizando a recomendação pedagógica. Para este curso de extensão serão convidados a participar estudantes e professores do curso de Licenciatura em Matemática, como também professores egressos do mesmo. Serão selecionados ou construídos OA para a construção das competências desejadas através do recomendador RecOAComp. Por fim, serão apresentados os resultados a partir das coletas dos dados obtidos na aplicação, realizada a análise e obtidas as conclusões e considerações finais, assim como possibilidades de trabalhos futuros.

\section{Resultados e contribuições esperadas}

Como resultado dessa pesquisa, além da criação da matriz de competências, é esperado que a recomendação pedagógica a ser aplicada traga resultados satisfatórios. A originalidade deste trabalho consiste na construção dessa matriz de competências docentes em matemática por meio do ensino híbrido e a recomendação pedagógica a partir dessa matriz.

As contribuições desta pesquisa estão no apoio aos processos de ensino e de aprendizagem, através da personalização possibilitada pelo SRE; na melhoria dos processos de avaliação, devido ao atendimento das necessidades do aluno; na criação da matriz de competências docentes em matemática; na possibilidade de ampliação da utilização da recomendação pedagógica em outros níveis de ensino e área do conhecimento.

\section{Referências}

BACICH, L.; NETO, A. T.; TREVISANI, F. Ensino Híbrido: Personalização e Tecnologia na Educação. Porto Alegre: Penso Editora, 2015.

BEHAR, P.A. et al. Competências em Educação à Distância. Porto Alegre: Penso, 2013.

CAZELLA, S.C. et al. Desenvolvendo um Sistema de Recomendação de Objetos de Aprendizagem baseado em Competências para a Educação: relato de experiências. In: 23o Simpósio Brasileiro de Informática na Educação, Rio de Janeiro, RJ, 2012. Disponível em ie.org/pub/index.php/sbie/article/view/1710> Acesso em 07/05/19.

MORAN, José. Metodologias ativas para aprendizagem mais profunda. In: BACICH, Lilian; MORAN, José Metodologias ativas para uma educação inovadora. Porto Alegre: Penso. 2018.

PERRENOUD, Philippe. Dez Novas Competências para Ensinar. Porto Alegre: Artmed Editora, 2000.

PIAGET, Jean. Psicologia da inteligência. 2. ed. Tradução de Egléa de Alencar. Rio de Janeiro: Fundo de Cultura, 1972, p. 93.

ZABALA, A.; ARNAU, L. Como aprender e ensinar competências: uma proposta para o currículo escolar. Porto Alegre: Artmed, 2010. 